\title{
Air-insufflated high-definition dacryoendoscopy yields significantly better image quality than conventional dacryoendoscopy
}

This article was published in the following Dove Press journal:

Clinical Ophthalmology

I August 2017

Number of times this article has been viewed

Tsugihisa Sasaki'

Tsutomu Sounou ${ }^{2}$

Hideki Tsuji ${ }^{3}$

Kazuhisa Sugiyama ${ }^{4}$

'Sasaki Eye Clinic, Mikuni, Sakai, ${ }^{2}$ Department of Ophthalmology, Keiju Kanazawa Hospital,

${ }^{3}$ Department of Ophthalmology, Cancer Institute Hospital,

${ }^{4}$ Department of Ophthalmology and Visual Science, Kanazawa University Graduate School of Medical Science, Kanazawa, Japan

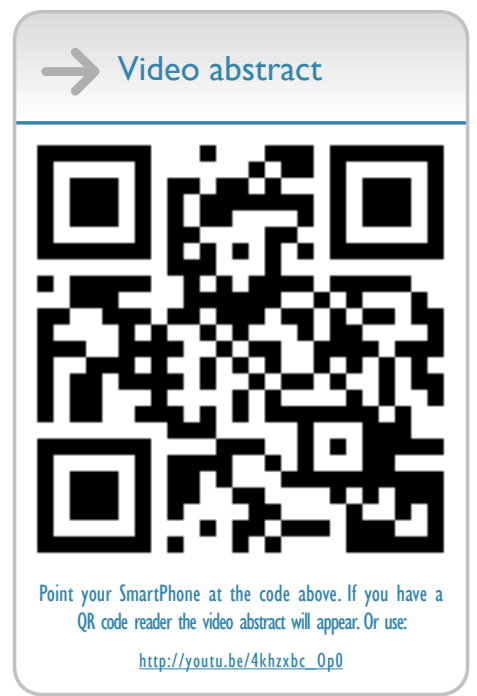

Correspondence: Tsugihisa Sasaki Sasaki Eye Clinic, 5-2-6 Mikuni-higashi, Mikuni, Sakai 913-0016, Japan

Tel +8I 776880033

Fax +8I 776880233

Email sasatsug@sound.ocn.ne.jp
Purpose: To facilitate the analysis of lacrimal conditions, we utilized high-definition dacryoendoscopy (HDD) and undertook observations with a pressure-controlled air-insufflation system. We report the safety and performance of HDD.

Methods: In this retrospective, non-randomized clinical trial, 46 patients (14 males and 32 females; age range 39-91 years; mean age \pm SD $70.3 \pm 12.0$ years) who had lacrimal disorders were examined with HDD and conventional dacryoendoscopy (CD). The high-definition dacryoendoscope had 15,000 picture element image fibers and an advanced objective lens. Its outer diameter was $0.9-1.2 \mathrm{~mm}$. Air insufflation was controlled at $0-20 \mathrm{kPa}$ with a digital manometer-based pressure-controlled air-insufflation system to evaluate the quality of the image. The HDD had an air/saline irrigation channel between the outer sheath (outer diameter $=1.2 \mathrm{~mm}$ ) and the metal inner sheath of the endoscope. We used it and the CD in air, saline, and diluted milk saline with and without manual irrigation to quantitatively evaluate the effect of air pressure and saline irrigation on image quality.

Results: In vivo, the most significant improvement in image quality was demonstrated with air-insufflated (5-15 kPa) HDD, as compared with saline-irrigated HDD and saline-irrigated CD. No emphysema or damage was noted under observation with HDD. In vitro, no significant difference was demonstrated between air-insufflated HDD and saline-irrigated HDD. In vitro, the image quality of air-insufflated HDD was significantly improved as compared with that of saline-irrigated CD.

Conclusion: Pressure-controlled (5-15 kPa) air-insufflated HDD is safe, and yields significantly better image quality than CD and saline-irrigated HDD.

Keywords: pressure-controlled air-insufflated, high-definition dacryoendoscopy, saline-irrigated dacryoendoscopy, emphysema

\section{Introduction}

Lacrimal infections can cause serious visual discomfort and disability. For the purpose of selecting appropriate surgical procedure, it is extremely important to know the location and cause of lacrimal obstruction. Lacrimal irrigation, probing, dacryocystography, and nasal endoscopy are not adequate to locate the obstruction in themselves. Direct visualization of the lacrimal passage has been a diagnostic tool since the 20th century.

Dacryoscopy was established first by Cohen et al. ${ }^{1}$ Its illumination, however, was delivered with percutaneous light fiber illumination. Improved dacryoendoscopes and instruments for simultaneous treatment have been devised. ${ }^{2-5}$ Better visualization will improve the analysis of lacrimal conditions, that is lacrimal tumor detection, 
identification of an obstructed canalicular site before probing, quantitative diagnosis of lacrimal mucosa, etc.

However, there is a significant gap in visualization between the nasal endoscope and the dacryoendoscope. A limited number of picture elements and non-quantitative saline irrigation pressures are thought to be drawbacks of dacryoendoscopy at diagnosis and treatment.

To overcome the low visualization, we adopted airinsufflated dacryoendoscopy instead of saline-irrigated dacryoendoscopy, and used a modified dacryoendoscope system - that is, a higher picture element, new objective lens, and controlled pressure air-insufflated dacryoendoscopy. ${ }^{6}$ In this study, we compared pressure-controlled air-insufflated high-definition dacryoendoscopy, saline-irrigated highdefinition dacryoendoscopy and saline-irrigated conventional dacryoendoscopy.

\section{Methods}

\section{Patients}

Forty-six patients (14 males and 32 females; age range 39-91 years; mean age \pm SD $70.3 \pm 12.0$ years) with lacrimal disorders (primary nasolacrimal duct obstruction, common canalicular obstruction or stenosis, and punctal obstruction) who underwent high-definition dacryoendoscopy (HDD) or/and conventional dacryoendoscopy (CD) in an outpatient setting were enrolled. Pregnant women and children were excluded. The diagnosis of a lacrimal disorder was established on the basis of a history of epiphora or discharge, tear meniscus height, dacryoendoscopic findings, and results of lacrimal irrigation. All patients were evaluated and underwent lacrimal surgery - dacryocystorhinostomy, canaliculoplasty, and punctoplasty - between December 2014 and September 2016. Medical records were used as an additional source of information, and informed consent was obtained from all patients. The study protocol and data collection methods were approved by the Institutional Review Board of Keijyu Kanazawa Hospital.

\section{Patient evaluation}

Patients were thoroughly examined by an ophthalmologist (TS) and underwent a comprehensive ophthalmologic examination, including ocular surface fluorescein staining, probing, and lacrimal irrigation. Details of the dacryoendoscopic procedure used in the present study are described elsewhere. ${ }^{7}$ Briefly, after instillation of oxybuprocaine (Benoxil ${ }^{\circledR} 0.4 \%$, Santen, Osaka, Japan), anesthesia along the infratrochlear nerve distribution was obtained with a mixture of $0.001 \%$ epinephrine and $1 \%$ lidocaine (Xylocaine ${ }^{\circledR}$ injection $1 \%$ with epinephrine,
Astra Zeneca, Osaka, Japan), and the upper and lower lacrimal puncta were dilated gently with a punctal dilater. The dacryoendoscope (Fibertech Co., Tokyo, Japan) was inserted through the upper and/or lower canaliculus to minimize iatrogenic canalicular damage due to insertion of the HDD.

\section{HDD and CD}

We used the new, custom-made, high-definition dacryoendoscope for HDD. The high-definition dacryoendoscope (outer diameter $=0.9-1.2 \mathrm{~mm}$, Figure 1) had 15,000 picture elements and $60^{\circ}$ field of view, and a compound lens was used as an objective lens instead of a Selfoc lens. There was no irrigation channel in the metal sheath; saline or air was irrigated with a custom-made irrigation sheath (outer diameter $=1.2 \mathrm{~mm}$, Figure 1). Saline was injected manually through the channel for clear viewing of the lumen and evaluation of lacrimal extensibility. In cases involving air-insufflation dacryoendoscopy (Figure 1), air pressure was controlled and monitored continuously with the digital manometer-based pressure-controlled air-insufflation system - comprising an air pump (HA-735C, Hapyson, Chiba, Japan; maximum flow volume: 1,500 $\mathrm{mL} / \mathrm{min}$, maximum pressure: $50 \mathrm{kPa}$ ), relief valve, a digital manometer (EM-150W; Hodaka, Osaka, Japan), and a PC. Under dacryoendoscopy, the air pressure was controlled to evaluate the appropriate air pressure $(0-20 \mathrm{kPa})$. When the lacrimal mucosa was perforated, the high-definition dacryoendoscope was withdrawn from the lacrimal pathway as soon as possible to avoid causing emphysema. The use of saline or air was easily changed with a three-way stopcock. Saline irrigation was used at surgery, and air-insufflation was used at observation mainly to avoid causing emphysema. Lid swelling of patients was always observed by a nurse to detect emphysema. In cases with lacrimal punctal obstruction, air-insufflated HDD was performed at the common canaliculus, sac, and duct. The probe of the dacryoendoscope was gradually bent at a $20^{\circ}-25^{\circ}$ angle from the tip (Figure 1). The reason for the curvature was to avoid contact with the supraorbital margin and the medial palpebral ligament when the dacryoendoscope was inserted into the nasolacrimal duct. ${ }^{8,9}$

A conventional dacryoendoscope (outer diameter $=0.9 \mathrm{~mm}$, 10,000 picture elements, $60^{\circ}$ field of view, objective lens $=$ Selfoc lens) was used, as previously mentioned. ${ }^{7}$ The same object was captured with each dacryoendoscope for comparison.

Dacryoendoscopic images were converted and recorded with an AD convertor (VUC-02; IDK, Kanagawa, Japan) and a digital image recorder (HVO-1000MD; Sony, Tokyo, 

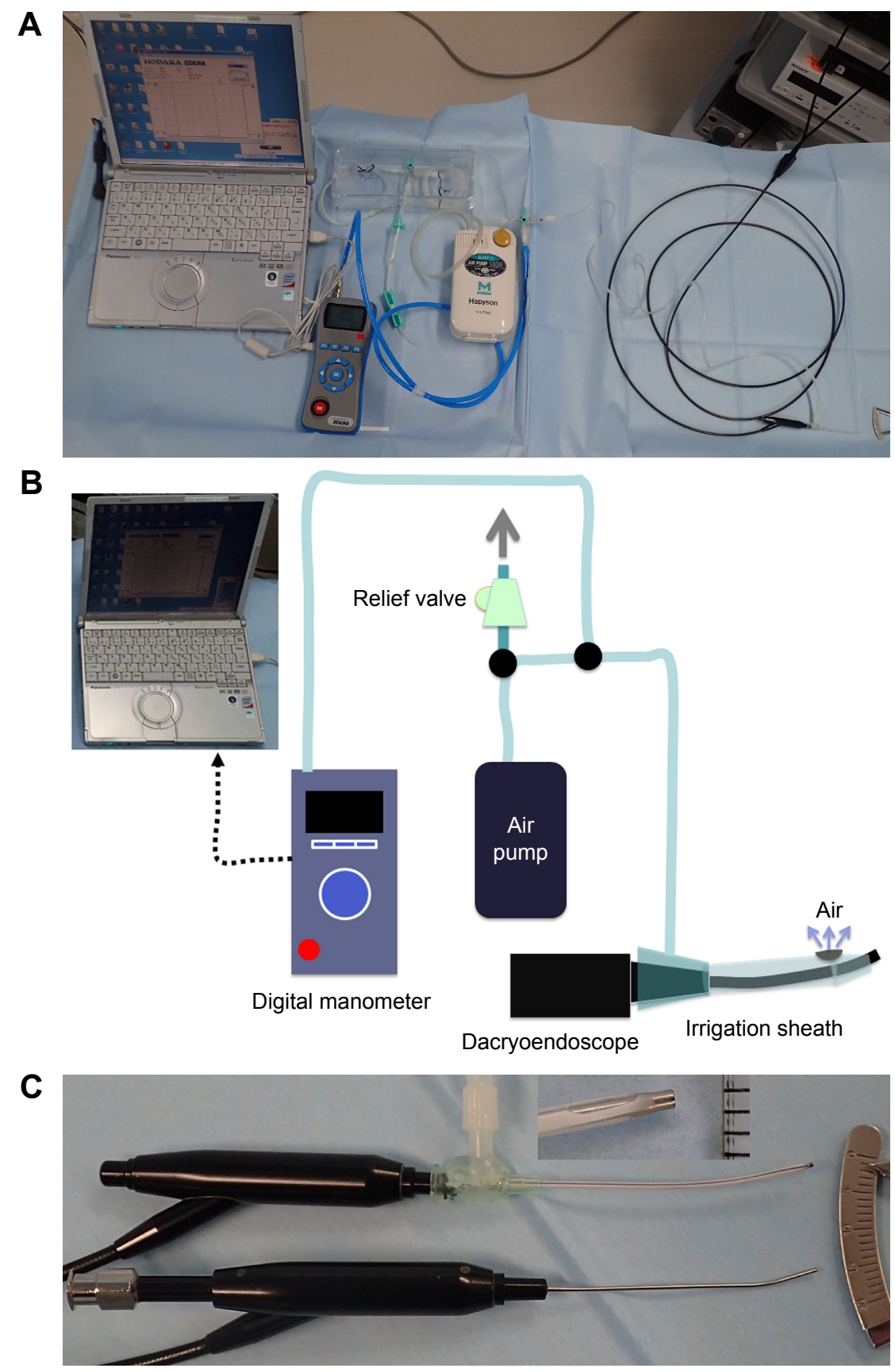

Figure I Instruments used to perform dacryoendoscopy. (A) The digital manometer-based pressure-controlled air-insufflation system. The digital manometer and relief valve were connected to the air tube with a three-way stopcock. (B) The schema of the digital manometer-based pressure-controlled air-insufflation system. (C) Photograph of the high-definition dacryoendoscopes: the high-definition dacryoendoscope with custom-made sheath (top and inset) and the conventional dacryoendoscope (bottom).

Japan). Individual image frames (.tif) were subsequently extracted from the video file for analysis. A $100 \mathrm{~W}$ Xenon light source was used (FT-203F ${ }^{\circledR}$; Fibertech Co., Tokyo, Japan).

\section{In vitro experiment}

\section{Image quality analysis with each dacryoendoscope}

We compared the image resolution (line pairs per millimeter) of the dacryoendoscopes (HDD and CD) by imaging a test chart (3M550, Pearl optical industry, Tokyo, Japan; Figure 2).
Both the high-definition dacryoendoscope and the conventional dacryoendoscope were fixed with a clamp, and the distance between the dacryoendoscope and the object was adjusted optimally.

\section{Picture resolution analysis in each condition}

The effects of irrigation and the difference of the medium on the image quality of the HDD and the CD were investigated. We assessed four patterns of dacryoendoscopy: 1) in air, 

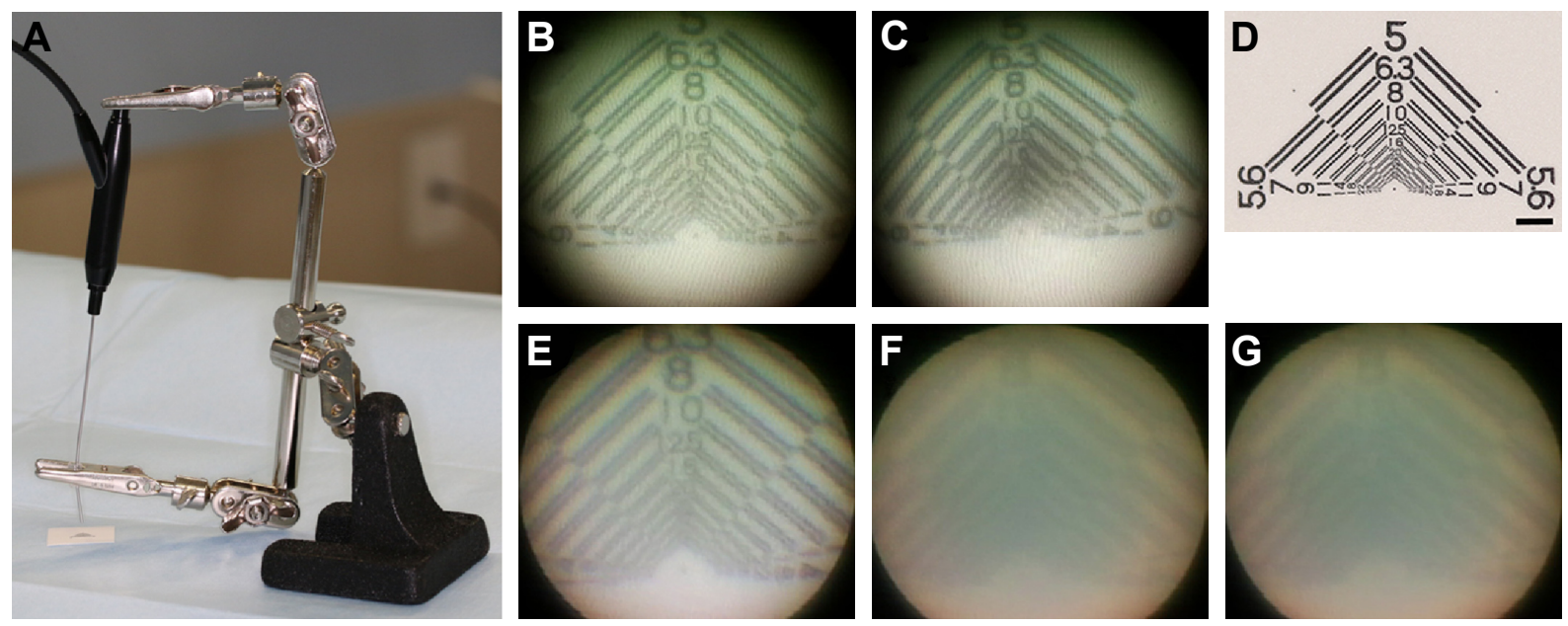

Figure 2 In vitro experiment with high-definition dacryoendoscopy (HDD) and conventional dacryoendoscopy (CD). Test bench, image of HDD and CD in air, saline, and 100-fold diluted milk saline (DMS). (A) Test bench to measure the optical resolution of HDD and CD. (B) The image of HDD in saline. (C) The image of HDD in air. (D) The image of the resolution target (scale bar: I mm). (E) The image of CD in saline with optimum illumination intensity. (F) The image of CD in DMS with irrigation and optimum illumination intensity. (G) The image of CD in DMS without irrigation and optimum illumination intensity.

2) in saline, 3) in 100-fold diluted milk saline (DMS 1\%) without saline irrigation and optimum illumination intensity, and 4) in DMS with saline irrigation and optimum illumination intensity (Figure 2). We analyzed the power of resolution and contrast in each condition from these photographs of the test chart. The pressure of manual saline irrigation was $50-100 \mathrm{kPa}$. DMS simulates turbidity in the lacrimal pathway.
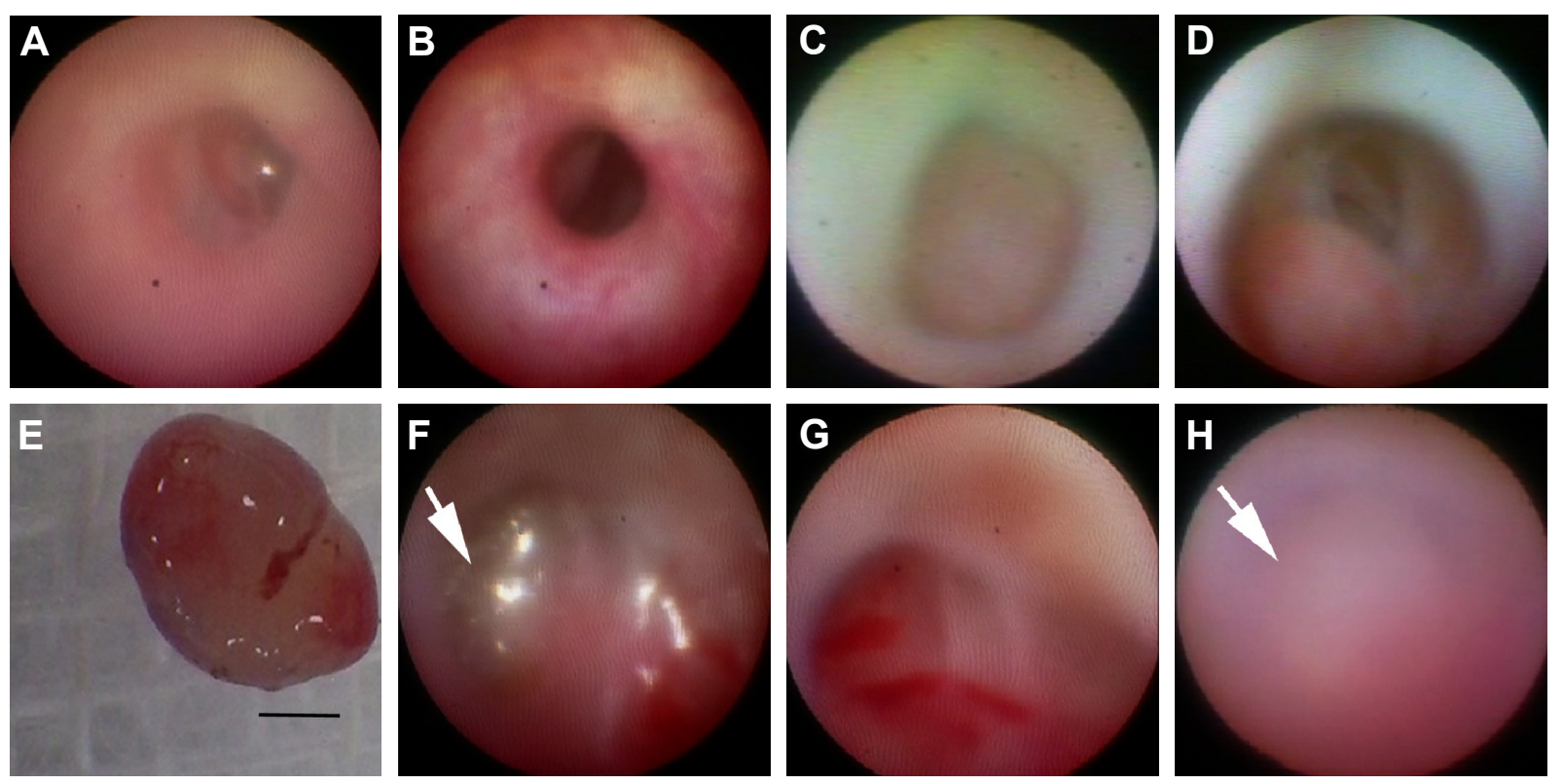

Figure 3 Images of air-insufflated HDD, saline-irrigated HDD, and saline-irrigated CD. (A) Saline-irrigated image of the nasolacrimal duct with HDD. The inferior part of the nasolacrimal duct stenosis was captured. (B) Air-insufflated (I5 kPa) image of the duct with the HDD. The same region of Figure $3 \mathrm{~A}$ was captured. The vascular pattern is expressed in a more detailed image. (C) Image of a granuloma with CD. This image was enlarged to the same size as that in Figure 3D for comparison. (D) Image of a granuloma with $15 \mathrm{kPa}$ in the air-insufflated HDD. A plexus of vessels on the granuloma was identified. (E) Microscopic photo of an excised granuloma after DCR (scale bar $=1 \mathrm{~mm}$ ). (F) Air-insufflated image ( $15 \mathrm{kPa}$ ) of common canalicular obstruction with HDD. The white lesion (arrow) indicates membranous obstruction. (G) Salineirrigated image of common canalicular obstruction with HDD. The same region as in Figure $3 \mathrm{~F}$ was captured. Blood coagulation accumulated at the pit of the common canaliculus. (H) Saline-irrigated image of CD. The same region of Figure $3 \mathrm{~F}$ was also captured. The white lesion (arrow) indicates membranous obstruction. The image appears vague. This image was enlarged to the same size as in Figure $3 \mathrm{~F}$ for comparison. 

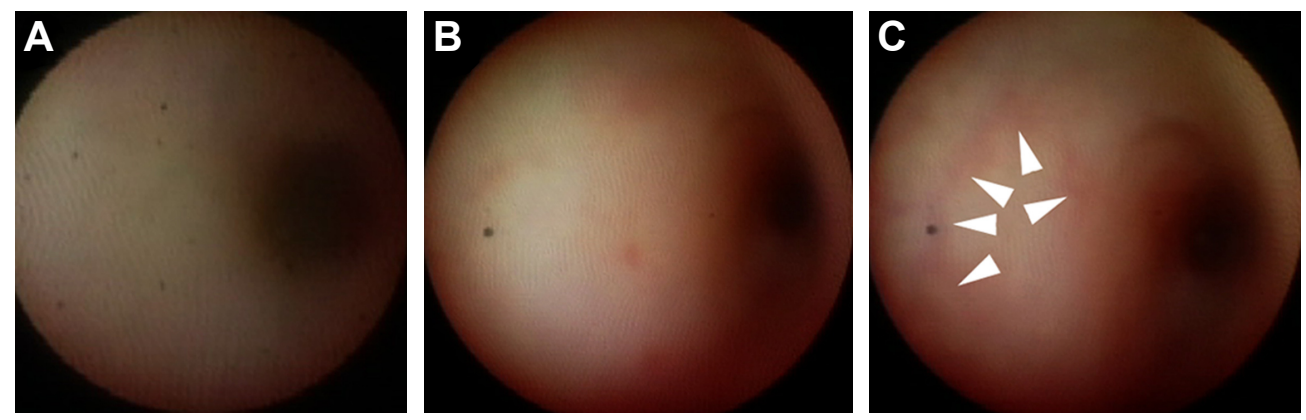

Figure 4 (A) Saline-irrigated image of the lacrimal sac with CD. The sac mucosa appears avascular. This image was enlarged to the same size as in Figure 4B for comparison. (B) Air-insufflated image $(20 \mathrm{kPa})$ of the sac with the HDD. The same region of Figure 4A was captured. The sac mucosa appears avascular but florid. (C) Air-insufflated image $(5 \mathrm{kPa})$ of the sac with the HDD. The same region as in Figure 4A was captured. A plexus of vessels on the nasolacrimal duct was identified (arrowheads).

with nasolacrimal stenosis. Air-insufflated $(15 \mathrm{kPa}) \mathrm{HDD}$ demonstrated a vascularized mucosal image of nasolacrimal stenosis when compared with the saline-irrigated HDD image (Figure 3). To investigate the value of tumor detection using air-insufflated HDD, we observed patients with granuloma. In a patient who underwent postoperative dacryocystorhinostomy (DCR), a small granuloma was visualized at the common canaliculus rather than at the anastomosis site. The granuloma was compressed by saline irrigation pressure, and air-insufflated dacryoendoscopy liberated the granuloma from the lacrimal inner wall (Figure 3). The image obtained with the air-insufflated HDD was more similar, in color, to the microscopic image of the granuloma extracted at DCR than to the image obtained with the saline-irrigated CD (Figure 3).

In patients with common canalicular obstruction, the obstructed sites were analyzed with air-insufflated HDD, saline-irrigated HDD, and saline-irrigated CD. Moreover, air-insufflated HDD and saline-irrigated HDD provided fine images at the common canaliculus (Figure $3 \mathrm{~F}$ and $\mathrm{G}$ ). The image quality of air-insufflated HDD was clearer than that of saline-irrigated HDD. The obstructed site was identified as an avascular white lesion, surrounded by vascularized mucosa. On the other hand, obviously, saline-irrigated HDD demonstrated a somewhat vague and avascularized image as compared with the air-insufflated HDD image. Saline irrigation, furthermore, failed to remove the blood at the pit of the common canaliculus. The image captured was of the same region. Thus, saline-irrigated CD showed a significantly vague and low-quality image.

Second, relationships between image quality and air pressure level were investigated. The vascular pulsation and canalicular/sac movement during blinking became visible at lower air pressures $(5 \mathrm{kPa})$. Higher air pressures $(15-20 \mathrm{kPa})$ enabled a better, but avascular, image due to ductal extension (Figure 4). With the saline-irrigated CD, the image captured the same region, but it was just an avascular image (Figure 4).
Lower air pressures $(<4 \mathrm{kPa})$ caused insufficient space for dacryoendoscope insertion and observation.

There was no damage to the external appearance of HDD and image quality after dacryoendoscopy. No complications in our stated condition, such as postoperative bleeding, infection, subcutaneous emphysema, or inflammation, were noted.

In an in vitro experiment, the HDD image quality in saline and air showed similar resolution and contrast (18 line pairs/mm; Figure $2 \mathrm{~B}$ and $\mathrm{C}$ ). The image contrast quality with HDD in air was significantly better than that with $\mathrm{CD}$ in saline (Figure $2 \mathrm{C}$ and $\mathrm{E}$ ). The image resolution of HDD in air and $\mathrm{CD}$ in saline did not show significant differences (18 line pairs/mm vs 18 line pairs/mm; Figure 2C and E). $\mathrm{CD}$ in DMS with or without irrigation showed a similar resolution of 8 line pairs/mm (Figure $2 \mathrm{~F}$ and $\mathrm{G}$ ).

\section{Discussion}

Our results indicate that the air-insufflated HDD system has a higher potential than the saline-irrigated CD to diagnose lacrimal passage disorders. The air-insufflated HDD could facilitate a clearer view of the field by avoiding blood, mucus, or pus dispersion in the sac and duct. In addition, a clear view was created by appropriate ballooning of the lacrimal pathway with the air insufflation system, and appropriate air pressure enabled capture of the vascular image. Therefore, the air-insufflated HDD system has the potential to detect smaller lesions than the saline-irrigated HDD or CD systems. Furthermore, the HDD system can be used in a similar way to a simple microscope based on its image quality.

When we compared the in vivo dacryoendoscopic images among HDD, CD, and a macro mode-digital camera, we used patients with lacrimal granuloma who were post DCR instead of patients with an apparent lacrimal tumor, because lacrimal tumors are too rare and too difficult for a macroscopic photo to be useful after removal. Differences in the quality 
of the granuloma images suggested that air-insufflated HDD provides better images for definitive diagnosis.

In common canalicular obstruction, dacryoendoscopic incision and successive intubation is an effective treatment. Precise identification of the obstructed lesion is the key to a successful surgery. ${ }^{5}$ Air-insufflated HDD facilitates easier identification of obstructed lesions than $\mathrm{CD}$ or salineirrigated HDD. However, air-insufflated HDD should be converted to saline-irrigation during canalicular incision to avoid emphysema.

Endoscopies in the human body are classified as airinsufflated and saline-irrigated, based on the anatomic condition, image quality, and operability. The lacrimal passage is located between the air (nasal cavity) and water environment (tear meniscus), suggesting that the dacryoendoscope should be calibrated for each phase on the basis of these features. Neither the limitation of water irrigation on image quality nor the air pressure of dacryoendoscopy has ever been discussed quantitatively.

In in vitro experiments, the image quality obtained with the HDD in air is similar to that obtained with the HDD in saline. On the other hand, in the in vivo experiment, air-insufflated HDD had better image quality than salineirrigated HDD. There is a discrepancy between the results obtained in vivo and in vitro. This discrepancy suggests that even the lacrimal pathway, with or without bleeding/ purulence, has slight turbidity because of its mucus and that saline irrigation should have an insufficient effect on turbidity removal in the visual field. The image quality of $\mathrm{CD}$ with saline and without saline irrigation in $1 \%$ DMS was also similar. This result, in addition, suggests the limitation of turbidity removal with saline irrigation. This limitation may be caused by a low clearance of saline and blood coagulability in the lacrimal pathway. Even in the case of slightly turbid media, this limitation should cause a blurred dacryoendoscopic image in vivo. In vitro, the image quality obtained with HDD in air was also better than that with $\mathrm{CD}$ in saline. The contrast between HDD and CD might be caused by the difference in the number of picture elements, objective lens (combination lens vs Selfoc lens), or coaxial illumination with the HDD versus collateral illumination with the $\mathrm{CD}$. To summarize these findings, complete removal of turbid media by air insufflation, use of a clear objective lens, the illumination system difference, and a larger image in HDD should be the main factors for clear viewing.

Since 1992, saline-irrigated lacrimal endoscopy has facilitated the detection of pathologic conditions; ;,7,10 however, saline-irrigated lacrimal endoscopy can only detect these sites qualitatively because of the low number of picture elements and dispersion of blood or mucus in the sac and duct by turbulent flow. Moreover, saline-irrigated dacryoendoscopic images sometimes lack capillary images, because hydro-pressure compresses the plexus of vessels completely to stop bleeding from the mucosa of the sac.

On the other hand, the higher air-pressure in dacryoendoscopy refines the image quality of nasolacrimal obstruction and common canalicular stenosis/obstruction or dacryolith by stretching the lacrimal mucosa. However, the higher the air pressure, the higher the risk of emphysema in the case of a perforated lacrimal mucosa. The appropriate hydro- or air-pressure was 5-10 $\mathrm{kPa}$ in vitrectomy, $20-50 \mathrm{kPa}$ in laparoscopic surgery, and $20 \mathrm{kPa}$ in gastric endoscopy, in the interests of hemostasis and blood supply. To avoid emphysema, air-insufflated HDD is used only in the observation phase. In the surgical phase, or in case of mucosal perforation, saline-irrigated HDD should replace air insufflation. The present study suggests that the appropriate air pressure is $5-15 \mathrm{kPa}$, because the appropriate pressure should be applied by inflation of the lacrimal passage, blood pressure, and lacrimal pump pressure generated by blinking. ${ }^{11}$

Furthermore, for tumor detection and evaluation, it is important to detect changes in the hue of the mucosa, neovascularization, shape, or ulceration. ${ }^{12-14}$ Differences in media and air pressure significantly affected the quality of the image in HDD. Thus, we should carefully select suitable media for dacryoendoscopy and an optimum air pressure level for evaluation of lacrimal tumors or other diseases. Lack of availability of the pressure-controlled air-insufflated HDD system and its time-consuming set-up are disadvantages; however, these disadvantages are considered to be merely technical, because the pressure-controlled air-insufflated HDD system comprises known mechanisms, and due to the readily available characteristics of these mechanisms, set-up of an air-insufflation system will be convenient.

For further improvements, the HDD could provide a disposable detachable irrigation channel. It suggests that the HDD has a completely disinfectable structure. Some colon or gastric endoscopes have bacterial contamination in the channel, even after high-level sterilization. ${ }^{15}$ Because gastric endoscopes are complicated instruments with internal channels, complete disinfection is difficult to achieve.

In summary, the advantages of pressure-controlled airinsufflated HDD are good image quality and avoidance of irrigation channel contamination. Disadvantages include the very low but serious risk of emphysema, the limitation of 
usage to the observation phase, the level of labor required for set-up, and unavailability of pressure-controlled airinsufflated HDD in the market.

\section{Disclosure}

TS received material support for this study from Fibertech. The authors report no other conflicts of interest in this work.

\section{References}

1. Cohen SW, Prescott R, Sherman M, Banko W, Castillejos ME. Dacryoscopy. Ophthalmic Surg. 1979;10(11):57-63.

2. Fein W, Daykhovsky L, Papaioannou T, Beeder C, Grundfest WS. Endoscopy of the lacrimal outflow system. Arch Ophthalmol. 1992; 110(12):1748-1750.

3. Kuchar A, Novak P, Pieh S, Fink M, Steinkogler FJ. Endoscopic laser recanalisation of presaccal canalicular obstruction. Br J Ophthalmol. 1999;83(4):443-447.

4. Javate RM, Pamintuan FG, Cruz RT Jr. Efficacy of endoscopic lacrimal duct recanalization using microendoscope. Ophthal Plast Reconstr Surg. 2010;26(5):330-333.

5. Sasaki T, Sounou T, Sugiyama K. Dacryoendoscopic surgery and tube insertion in patients with common canalicular obstruction and ductal stenosis as a frequent complication. Jpn J Ophthalmol. 2009; 53(2): 145-150.

6. Sens FM, Rol PO, Yanar A, Robert YC. [Rigid GRIN-endoscope for endoscopy of the tear ducts]. Klin Monbl Augenheilkd. 2000;216(5): 301-304. German [with English abstract].
7. Sasaki T, Nagata Y, Sugiyama K. Nasolacrimal duct obstruction classified by dacryoendoscopy and treated with inferior meatal dacryorhinotomy. Part I: positional diagnosis of primary nasolacrimal duct obstruction with dacryoendoscope. Am J Ophthalmol. 2005;140(6): 1065-1069.

8. Sasaki T. Dacryoendscopic observation of the lacrimal path and dacryoendope-assisted silicone intubation. Ganka. 1999;41(12): $1587-1591$

9. Narioka J, Matsuda S, Ohashi Y. Inclination of the superomedial orbital rim in relation to that of the nasolacrimal drainage system. Ophthalmic Surg Lasers Imaging. 2008;39(2):167-170.

10. Ashenhurst ME, Hurwitz JJ. Lacrimal canaliculoscopy: development of the instrument. Can J Ophthalmol. 1991;26(6):306-308.

11. Takahashi Y, Suzuki T, Kakizaki H. Lacrimal sac movement under intrasac pressure changes observed with dacryoendoscopy. Ophthal Plast Reconstr Surg. 2014;30(4):313-314.

12. Tanigawa N, Matsumura M, Amaya $\mathrm{H}$, et al. Tumor vascularity correlates with the prognosis of patients with esophageal squamous cell carcinoma. Cancer. 1997;79(2):220-225.

13. Shields JA, Shields CL. Tumors of the lacrimal drainage system. In: Shields JA, Shields CL, editors. Eyelid, Conjunctival, and Oribtal Tumors. 2nd ed. Philadelphia, PA: Lippincott Williams and Wilkins; 2008:231-242

14. Shields JA, Shields CL. Premalignant and malignant tumors of eyelid epidermis. In: Shields JA, Shields CL, editors. Eyelid, Conjunctival, and Orbital Tumors. 2nd ed. Philadelphia, PA: Lippincott Williams and Wilkins; 2008:19-48.

15. Chiu KW, Tsai MC, Wu KL, Chiu YC, Lin MT, Hu TH. Surveillance cultures of samples obtained from biopsy channels and automated endoscope reprocessors after high-level disinfection of gastrointestinal endoscopes. BMC Gastroenterol. 2012;12:120.
Clinical Ophthalmology

\section{Publish your work in this journal}

Clinical Ophthalmology is an international, peer-reviewed journal covering all subspecialties within ophthalmology. Key topics include: Optometry; Visual science; Pharmacology and drug therapy in eye diseases; Basic Sciences; Primary and Secondary eye care; Patient Safety and Quality of Care Improvements. This journal is indexed on

Submit your manuscript here: http://www.dovepress.com/clinical-ophthalmology-journal

\section{Dovepress}

PubMed Central and CAS, and is the official journal of The Society of Clinical Ophthalmology (SCO). The manuscript management system is completely online and includes a very quick and fair peer-review system, which is all easy to use. Visit http://www.dovepress.com/ testimonials.php to read real quotes from published authors. 